\title{
Una visión interdisciplinar del Madrid del Siglo de Oro: ideología, sociedad y fiesta cortesana a través de las relaciones de sucesos $^{1}$
}

\author{
María MOYA GARCÍA \\ Universidad Complutense de Madrid \\ maria.mg88@gmail.com
}

\begin{abstract}
RESUMEN
En el presente artículo se pretende realizar un estudio sobre una de las relaciones de sucesos que se escribieron con motivo de la entrada triunfal de Mariana de Austria en Madrid tras su matrimonio con Felipe IV. Su finalidad es reconstruir desde un punto de vista interdisciplinar la sociedad y el ambiente de la Corte madrileña en un día festivo. Se persigue, en definitiva, un triple objetivo: presentar los avatares políticos y regios que rodearon al enlace y a la entrada; estudiar la fiesta cortesana como un universo interdisciplinario en el que se integran aspectos relacionados con la arquitectura, pintura, escultura, música, danza, poesía, teatro, etc., que conviven en la ciudad durante la celebración; demostrar cómo, a través de este tipo de textos, es posible realizar un estudio sociológico de la sociedad del S. XVII.
\end{abstract}

Palabras clave: Relaciones de sucesos, Siglo de Oro, interdisciplinariedad, fiesta cortesana, entrada triunfal, Mariana de Austria, Felipe IV.

\begin{abstract}
The purpose of this paper is to study one narrative of events (relación de sucesos) which was writting because of Mariana de Austria's triumphal entry in Madrid after her marriage to Felipe IV. We try to reconstruct the society and the enviroment in Madrid's Court in a festive day with an interdisciplinary point of view. We follow, in short, a triple objective: to present the political and royal ups and downs surrounding the link and the entry; to study the court party as an interdisciplinary universe in which different aspects related to architecture,
\end{abstract}

\footnotetext{
${ }^{1}$ Este trabajo se integra en la investigación realizada por el Grupo de Investigación de la Universidad Complutense de Madrid GLESOC (Literatura española de los Siglos de Oro), dirigido por el profesor José $\mathrm{M}^{\mathrm{a}}$ Díez Borque. Además, forma parte de la investigación que estoy llevando a cabo en mi tesis doctoral, titulada Relaciones de sucesos, literatura y fiesta cortesana entorno a la boda de Mariana de Austria con Felipe IV (1647-1649).
} 
painting, sculpture, music, dance, poetry, theatre, etc. are integrated, disciplines that coexist during the celebration; to show how, throw this kind of texts, it is possible to perform a sociologic study of the 17 th century's society.

Keywords: Narrative of events, 17th century, interdisciplinary, royal festival, triumphal entry, Mariana de Austria, Felipe IV.

En la actualidad, se ha hecho un enorme hincapié en los estudios interdisciplinares por constituir una visión innovadora que permite el análisis de un mismo fenómeno desde diversos puntos de vista. Su rigor, su alcance y las enormes posibilidades que ofrece han permitido que se convierta en una de las claves de la investigación actual. En el caso de los estudios literarios, esta perspectiva ha encontrado su parangón en los estudios comparativos entre la literatura, el cine y la música contemporáneos. Sin embargo, en los últimos años la crítica ha ido sacando a la luz infinidad de textos áureos de naturaleza híbrida, que permiten enfocar su estudio desde diversas ópticas, lo que ha provocado la necesidad de adoptar un punto de vista interdisciplinar a la hora de proceder a su análisis.

Un buen ejemplo de este tipo de documentos son las relaciones de sucesos, textos que narran sucesos (valga la redundancia) o acontecimientos puntuales, ocasionales, contemporáneos al momento de la redacción y cuyo fin es el de informar, entretener y conmover al lector. Además, en muchas ocasiones muestran una clara intención propagandística, constituyendo así un claro antecedente de la prensa periódica ${ }^{2}$.

Aunque presentan una tipología muy variada ${ }^{3}$, para esta ocasión me interesan especialmente las relaciones de sucesos festivas, en las que pretendía hacer un relato lo más minucioso posible de todos los acontecimientos que tenían lugar durante las fiestas cortesanas, para común noticia y memoria del pueblo. Su estudio proporciona una serie de datos de extraordinario interés para conocer el funcionamiento y la mentalidad de la sociedad de la época, al ofrecer una imagen de la celebración desde distintas perspectivas en el mismo momento en que se producen. Asimismo, constituyen un magnífico ejemplo de la relación existente entre literatura y sociedad, precisamente por el empleo de estos textos con un objetivo meramente propagandístico y de exaltación de la monarquía. Se trata, por tanto, de documentos puestos al servicio de poder y cuya función principal era la de transmitir al pueblo unos valores y una imagen predeterminada de la monarquía española, imagen que distaba mucho de constituir un fiel reflejo de la realidad.Por todo ello, considero que estos documentos constituyen un excelente punto de partida para un estudio interdisciplinar de la sociedad del siglo XVII.

\footnotetext{
${ }^{2}$ Pueden encontrarse otras definiciones del término en: V. Infantes (1996) y N. Pena Sueiro (2005).

${ }^{3}$ Para una taxonomía de las relaciones de sucesos, se remite a N. Pena Sueiro (2005)
} 
La finalidad de este artículo será el análisis de una de estas relaciones con el fin de reconstruir desde varios puntos de vista la sociedad y el ambiente de la Corte en un día festivo. Debido al ingente corpus de relaciones y a la gran cantidad de fiestas cortesanas que se sucedieron durante este siglo, he decidido centrarme en la descripción de una de ellas: la entrada de Mariana de Austria en la Madrid en 1649 tras su matrimonio con Felipe IV. Tanto la fiesta como el enlace se inscriben en un delicado momento para la monarquía y la sociedad española, lo que justifica la cantidad de textos que suscitó y su relevancia para el tema que concierne a este estudio.

Se han conservado más de una docena de relaciones de esta entrada, aunque, sin duda, la más importante(y en la que me centraré durante mi exposición) es la anónima Noticia del recibimiento y entrada de la reina nuestra señora doña Mariana de Austria en la muy noble y leal coronada villa de Madrid (Noticia) ${ }^{4}$, por ser la más extensa, completa y detallada de cuantas conservamos ${ }^{5}$. Constituye lo que Teresa Zapata ha denominado como "gran libro de fiesta", es decir, "el relato o crónica oficial de mayor extensión, con formato de libro en tamaño folio, dirigido a un público más restringido y proyectado para publicarlo con más tranquilidad, con una descripción amplia y detallada de todo cuanto el Ayuntamiento y los gremios habían discurrido y fabricado para tal ocasión, con la transcripción de versos, motes e inscripciones en latín y castellano, e ilustrado con grabados de los arcos y demás adornos (...)"

La relación nos ha llegado sin autor ni pie de imprenta y con una única estampa en la portada dibujada por Francisco de Rizi, grabada por Pedro de Villafranca e ideada por el propio Ramírez de Prado, tal como se indica al pie de la misma. Desde muy pronto su autoría suscitó una gran polémica, puesto que se atribuyó a Calderón de la Barca ${ }^{7}$. No obstante, todos los estudios indican que, aunque Calderón, sin lugar a dudas, participó en la organización de esta entrada e incluso debió de componer muchos de los versos que se distribuyeron por las arquitecturas efímeras, no

\footnotetext{
${ }^{4}$ Ofrezco entre paréntesis la cita abreviada. Para la referencia completa, véase la bibliografía final.

${ }^{5}$ La relación nos ha llegado sin autor ni pie de imprenta. Su autoría ha suscitado una gran polémica, puesto que se ha atribuido a Calderón de la Barca en diversas ocasiones. Aunque hoy seguimos sin estar seguros de su autoría, se ha desechado la idea de que el insigne dramaturgo sea su autor.

${ }^{6}$ T. Zapata (1999), p. 366. Respecto a las relaciones festivas en forma de libro, se remite también al artículo de S. López Poza (1999).

${ }^{7}$ Ya en 1682, solo un año después de la muerte del dramaturgo, Vera Tassis, en el prólogo de la Verdadera quinta parte de comedias de Don Pedro Calderón de la Barca, señalaba que "El [año] de 49, hallándose [Calderón] en Alba con el excelentísimo señor Duque, le mandó Su Majestad, por su Real Decreto, volver a la Corte y describir y trazar aquello célebres arcos triunfales para la feliz entrada de su augusta esclarecida esposa doña Mariana de Austria” (J. E.Varey y M. A. Salazar, 1966, p. 1).
} 
pudo ser el autor de la Noticia y se han barajado otros nombres como Lorenzo Ramírez de Prado $^{8}$ o Juan Alonso de Calderón ${ }^{9}$, sin que se hayan podido dar pruebas concluyentes en ninguno de los casos.

La entrada de Mariana de Austria ${ }^{10}$ en la Corte supuso el broche final del enlace de la joven reina con su tío, Felipe IV. En aquel momento el rey español sobrepasaba la cuarentena, por lo que le triplicaba la edad a su jovencísima sobrina "11 "hija del señor emperador Ferdinando III y de la señora emperatriz doña María, infanta de España" $"$, tal como se advierte en la relación. Fallecido el heredero español, el príncipe Baltasar Carlos, en 1646, y anteriormente su madre, la reina, era necesario un segundo matrimonio para lograr el ansiado sucesor. Tras largas disquisiciones ${ }^{13}$, el monarca optó por la que había sido prometida de su hijo, puesto que políticamente convenía estrechar lazos con la rama germano austriaca de la familia, con el fin de hacer frente a su enemigo común: Francia, que en estos momentos comenzaba a hacerse con la hegemonía europea en detrimento de España.

A pesar de que la entrada se inscribe en un periodo de decadencia y de penuria económica, tanto la ciudad como los gremios se volcaron para que resultase lo más espectacular posible. No hay que olvidar que las entradas triunfales constituyeron uno de los principales acontecimientos socioculturales del siglo XVII y una ocasión excepcional de propaganda monárquica. De esta forma, se debía preparar una fiesta cuya suntuosidad, magnificencia, pomposidad y ostentación reflejase la situación y el poder de la monarquía, o al menos, la imagen que ellos pretendían ofrecer tanto a sus súbditos como al resto de potencias extranjeras, razón por la que se desplegaban todos los medios posibles para convertir la entrada en un auténtico espectáculo público de primera magnitud, en el que se integraba arquitectura, pintura, escultura, poesía, música, danza, teatro, luminarias, fuegos artificiales, torneos, que nos permiten obtener una visión de conjunto de la ideología, la sociedad y la fiesta cortesana del Madrid del siglo XVII. Todos estos elementos, como veremos, se encuentran perfectamente descritos en la anónima relación, lo cual resulta lógico si tenemos en cuenta que su finalidad no era otra que la de contribuir a perpetuar y difundir el enorme poder del imperio español.

\footnotetext{
${ }^{8}$ Lorenzo Ramírez de Prado fue nombrado superintendente y protector de estas fiestas por el propio Felipe IV el 11 de mayo de 1649.

${ }^{9}$ Juan Alonso de Calderón era abogado de los Reales Consejos y del Consejo de la Inquisición y parece que cumplió un papel muy importante en la elaboración del programa iconográfico de la entrada.

${ }^{10}$ Para una biografía completa de Mariana de Austria se remite a L. Oliván (2006).

${ }^{11}$ Mariana de Austria había nacido en 1634 y Felipe IV en 1605.

${ }^{12}$ Noticia, p. 1

${ }^{13}$ Como advierte E. Borrego (2003), desde la boda por poderes hasta la entrada de la reina en Madrid hubieron de pasar más de dos años.
} 
La entrada tuvo lugar el lunes 15 de noviembre de 1649, día que amaneció soleado, si hemos de confiar en las relaciones conservadas ${ }^{14}$.

La ceremonia comenzó en la Puerta del Buen Retiro, lugar en el que se formaba la comitiva que debía acompañar a la reina durante su recorrido. El protocolo exigía que la reina entrase a montada sobre una jaca -y no en literas o carrozas- y que vistiese según la tradición española. La anónima relación hace especial hincapié no sólo en la vestimenta de Mariana de Austria, sino en la de la numerosa comitiva que la acompañaba, lo que pone de manifiesto el interés de los relatores por reflejar fielmente el ambiente de aquel día y lo que constituye una magnífica oportunidad para trasladar al lector actual a las costumbres de mediados del siglo XVII. De esta forma, gracias a la relación sabemos que Mariana lucía un hermoso "traje castellano, de saya entera, de manga redonda, por desembarazo del manejo de la rienda; era de nácar y plata, con joyas de inestimable precio, airoso el sombrero, con plumas blancas [...]". El relator va aún más lejos e incluso describe la vestimenta del caballo en el que montó la reina: "Era el de su Majestad un hermoso caballo blanco, al quien el color dio el nombre de Cisne [...]. Estaba cubierto de un rico terliz de terciopelo liso negro, bordado de oro y plata, colores de todo el aderezo, con un sillón de plata de martillo, curiosamente dorada y tallado de labores y molduras"15. En cuanto a la vestimenta de la comitiva, se pone un especial énfasis en describir la riqueza de joyas, telas y bordados: "Las libreas mezcladas en infinito número, componían una selva de matices, en quien tuvo la variedad tan de su parte al aplauso que no dio que obrar no a la costa ni al buen gusto, porque la confusión sola era la que, tiranizando para si la general aclamación, despreció la riqueza"16.

Llama la atención la minuciosidad con la que se va nombrando a cada uno de los miembros de la Corte que formaron la comitiva regia y qué posición ocupaban todos ellos respecto a la reina. Por señalar solo un ejemplo (de las varias páginas que dedica el relator), transcribo la disposición de las damas de la reina:

\begin{abstract}
Alrededor de su caballo [se refiere al de la reina] seis meninos a pie, después la camarera mayor y a su lado izquierdo, un cuerpo de caballo más atrás, el caballerizo mayor [...]. Inmediatamente a la camarera mayor, la señora doña Casilde Manrique, guarda mayor, a quien seguían las señoras doña Leonor de Pimentel, doña Mencía de la Cueva, Doña Leonor de Velasco, doña Luisa María de Carvajal, doña Inés de Lima, doña Luisa Osorio, Doña María Antonia de Vera, doña Giomar de Silva y doña Catalina de Vera $[\ldots]^{17}$
\end{abstract}

\footnotetext{
${ }^{14}$ Se hace mucho hincapié en el tiempo porque, según la relación, los días anteriores la lluvia había hecho peligrar la entrada. "Cesó la continua lluvia, que procuró muchas días estorbar, aunque en vano, los adornos de su felicísima entrada" (Noticia, p. 1).

${ }^{15}$ Noticia, p. 104.

${ }^{16}$ Noticia, p. 105-106.

${ }^{17}$ Noticia, p. 106.
} 
La alusión al orden de la comitiva y a las personas que la integraban no es un aspecto nada desdeñable, ya que reflejan fielmente aspectos relacionados con la política del momento (no hay que olvidar que la entrada de una reina era, ante todo, un acontecimiento político de primer orden). En la procesión participaban las autoridades civiles, la nobleza, las órdenes religiosas, autoridades eclesiásticas, etc., y en su conjunto se pretendía ofrecer una imagen jerarquizada de la sociedad y del lugar que cada uno ocupaba en ella. Así, en palabras de Bouza

las solemnidades de Corte, bien fueran fiestas o simples funciones protocolarias, debieron de tener un valor de diagnóstico del estado en el que la propia Corte se encontraba. Es decir, los lugares asignados en una procesión [...] podían ser leídos, casi cabría decir medidos, para hacer escrutinio de las posiciones que ocupaban los distintos grupos presentes en la Corte, puesto que estar cerca del monarca suponía, en consecuencia, la proximidad a su gracia y a sus $\operatorname{mercedes}{ }^{18}[\ldots]$.

Una vez la comitiva había recibido a la reina en la puerta del Buen Retiro, se formaba la procesión y la reina comenzaba su recorrido por el centro de la ciudad: atravesaba la carrera de San Jerónimo para llegar al Arco de la Puerta del Sol. Desde allí, partirían hacia el palacio del conde de Oñate, donde todo el cortejo se detenía para que la reina saludase al rey. Proseguía el recorrido por la Calle Mayor hasta llegar a la Almudena, donde la reina asistía al Te Deum interpretado por los músicos y cantores de la Real Capilla. La reina volvía a montar y continuaba hasta el Palacio Real, donde la esperaba el rey para acompañarla a sus aposentos, poniendo fin a un desfile que podía llegar a durar varias horas.

Uno de los elementos más espectaculares de la entrada eran las construcciones efímeras que se distribuían en lugares estratégicos a lo largo del recorrido. Se trataba de monumentos diseñados expresamente para la ocasión con la colaboración de los maestros de obras, escultores y artesanos al servicio del rey. Eran estructuras fabricadas con materiales baratos, como madera, lienzo, pasta de papel o yeso, que podían llegar hasta los $40 \mathrm{~m}$. de altura. Se pintaban imitando mármoles y jaspes de colores, de oro y plata y se decoraban con cuadros, estatuas, jeroglíficos, versos y escudos de gran contenido simbólico. La grandiosidad de sus dimensiones y su minuciosa ornamentación pretendían sorprender tanto al pueblo como a la reina y poner de manifiesto, una vez más, el dominio de la corona española. En el caso de la entrada de Mariana de Austria se construyeron cuatro arcos triunfales (pese a que lo habitual en otras entradas era que fuesen tres) que representaban las cuatro partes del mundo en las fachadas principales y los cuatro elementos predominantes en cada una de ellas en la parte posterior ${ }^{19}$. A ellos habría que sumar la Portada del

\footnotetext{
${ }^{18}$ F. Bouza (2000), p. 159.

${ }^{19}$ La elección del número, que también aparecerá de forma insistente en el resto de decoraciones, no fue casual, puesto que lo que se pretendía era enfatizar el cuestionado poder del
} 
Buen Retiro, la Torrecilla del Prado, el Monte Parnaso, la Perspectiva del Prado, las Gradas de San Felipe, la Puerta de Guadalajara, la Platería y la plaza del Palacio Real $^{20}$ y un buen número de estatuas y fuentes adornadas que completaban la decoración. La espectacularidad de todas ellas contribuían a reforzar el mensaje que se pretendía transmitir al pueblo: las virtudes del Felipe IV como soberano (exaltándose sobre todo sus conquistas y su lucha contra los herejes), la lealtad de la villa madrileña hacia sus monarcas y las funciones de la joven reina ${ }^{21}$.

Al concluir las celebraciones, se subastaban los materiales empleados, los cuadros, las esculturas y demás adornos, desapareciendo así este espacio ficticio y devolviendo a la villa a su vida cotidiana. Desafortunadamente, no se han conservado grabados y dibujos de las arquitecturas de esta entrada, por lo que las descripciones que aparecen en las relaciones cobran un papel fundamental. De hecho, la Noticia de la entrada de Mariana de Austria dedica más de 90 páginas a describir de forma pormenorizada no solo los arcos y demás arquitecturas, sino cada pintura, cada escultura y cada elemento decorativo que se dispuso durante el recorrido, lo que nos permite hacer una reconstrucción bastante exacta de todos los monumentos. Por señalar un ejemplo, me referiré a una de las pinturas que decoraban la fachada principal del cuarto arco, dedicado a América:

Cargaban en los pedestales dos pinturas de a dieciséis pies de alto y veinte de ancho. La de la mano derecha era del seño rey Don Fernando el Católico, sacado de un original de Alberto Durero. Estaba sentado en un rico trono, a cuyos pies Colón, con una mano en globos, agujas y cartas de marear, daba noticia del descubrimiento de las Indias, y con la otra, cartas de creencia y algunas llaves, en significación de los nuevos reinos que a su real dominio se ofrecían. A las espaldas de Colón, dos figuras, de Hércules y Baco, que por haber sido celebrados de la antigüedad como conquistadores de nuevas tierras y provincias, admiraban con su afecto aquellas felicidades $^{22}$.

La decoración se completaba con el apoyo de los vecinos, quienes no dudaban en contribuir a la creación de este espacio festivo con la decoración de"sus casas y

monarca, cuarto de su nombre. Así, mediante la construcción de estos cuatro arcos, se ponía de relieve que, a pesar de los últimos reveses político, Felipe IV continuaba conservando un vasto poder en cada una de las cuatro partes del mundo. Para un estudio completo de los arcos, se remite a T. Zapata (2008).

${ }^{20}$ No se pretende aquí una descripción exhaustiva de las construcciones efímeras ni de la fiesta en sí, sino ofrecer al lector una visión de conjunto de lo que fue la boda, con el fin de que pueda comprender mejor el estudio de las relaciones que se escribieron para la ocasión.

${ }^{21}$ Estas funciones eran mantener la paz entre las dos ramas austriacas de los Habsburgo, ayudar al rey en la lucha contra los herejes y, por encima de todo, dotar a la corona de un heredero varón.

${ }^{22}$ Noticia, p. 83. 
bocacalles, pues aquellas se vieron cubiertas de telas, brocados y colgaduras bordadas y tapicerías; y en la variedad de sus colores, a todas partes admirables pensiles; y desde sus alturas hasta el suelo, se desojaban rosas y se esparcían primaveras $[\ldots]^{23}$, lo que nos muestra la importancia que la sociedad española concedía a este tipo de acontecimientos. Además, en la relación se subraya el ambiente festivo y lúdico de la ciudad y la lealtad, la devoción y la veneración que mostraban los madrileños hacia su monarca ("la muchedumbre del pueblo, que con ansia de verle [se refiere al rey] se impedía, dio asi como pudo, con su amor y respeto, seguro paso a la majestad y a su agrado"24), lo que pone de manifiesto el carácter propagandístico del libro de la fiesta.

Además de la pintura y arquitectura, un elemento muy significativo de estas decoraciones era la poesía mural ${ }^{25}$. En palabras de Simón Díaz, se trataba de "poemas destinados a permanecer expuestos a la contemplación pública durante horas con motivo de solemnidades de carácter extraordinario" ${ }^{26}$. Fue cultivada por los mejores de poetas de la Corte $^{27}$, que trataban de aprovechar una ocasión de tal envergadura para darse a conocer y ganarse el favor real. Dado su carácter eminentemente efímero, la mayoría de ellas desaparecían con las decoraciones. No obstante, la Noticia transcribe la totalidad de las poesías, inscripciones, lemas, epigramas y emblemas que se dispusieron, tanto en latín como en castellano, en los arcos y demás decoraciones que conformaban el programa iconográfico, salvaguardando así esta valiosa literatura aurisecular.

La mayoría de estos poemas tienen una indudable raigambre clásica y una procedencia humanística, cumpliendo una doble función: unos eran composiciones meramente laudatorias, destinadas a exaltar las virtudes de la monarquía, entre las que destacan especialmente los poemas dedicados a la reina:

A la Cesárea austriaca gloriosa, siempre feliz augusta Mariana, de emperadores nieta soberana, del gran Felipe incomparable esposa.

A la que todos vienen generosa, y el bien de todos trae consigo ufana, con majestad tan gravemente humana, que a toda nuestra España hace dichosa.

\footnotetext{
${ }^{23}$ Noticia, p. 102

${ }^{24}$ Ibid.

${ }^{25}$ Utilizo el término acuñado por José Simón Díaz. Sin embargo, este tipo de manifestación literaria ha recibido otras denominaciones, como "poesía efímera" o "poesía visual" (J.M. Díez Borque, 1993).

${ }^{26}$ J. Simón Díaz (1977), p. 32.

${ }^{27}$ En el caso de la entrada de Mariana de Austria, sabemos que participaron poetas como Vélez de Guevara, Alonso de Calderón o Calderón de la Barca.
} 
Esta pompa, este obsequio, esta obediencia, en que al anciano, al joven y al infante, bastante lo vivido les parece.

Madrid, en culto amor y reverencia, hoy más postrada cuanto más triunfante, fiel rinde, leal consagra, humilde ofrece.

Otros eran versos destinados a aclara o explicar el significado de las estatuas y pinturas que se dispusieron en los arcos y demás decoraciones. Así, en uno de los cuadros del primer arco se pretendía ponderar las victorias de D. Pelayo sobre los infieles, y "en el remate superior de este cuadro había una tarjeta guarnecida de palmas y coronada de oro que la tenían dos cupidos de relieve, y en ella escritos estos versos:

Si aquí de Asturias, príncipe famoso, obra en infieles bélicos castigos, no menos que Pelayo virtuoso, Filipe vencerá a sus enemigos. Y si el destino influye generoso, en el blasón, los astros sean testigos, que a restaurar otras rebeldes furias nos de Alemania Príncipe de Austrias ${ }^{28}$

Durante todo el recorrido se organizaban una serie de fiestas y espectáculos para amenizar la procesión. Así, en las bocacalles y plazas por donde pasaba la reina, se alzaban tablados que servían de escenarios eventuales para todo tipo de representaciones teatrales, parateatrales, danzas y espectáculos pirotécnicos, que ralentizaban el paso de la comitiva y entretenía al público asistente. En el caso de esta entrada, sabemos que se dispusieron hasta 36 tablados que la relación describe en los siguientes términos: "en todas las bocacalles estaban con máscaras y danzas de diferentes trajes, instrumentos e invenciones sobre tablados, adornados de colgaduras y pinturas, cuya variedad, apenas en uno acababa cuando empezaba en otro" ${ }^{29}$. Además, la Noticia hace mención a un pequeño escenario que se situó frente al palacio del conde de Oñate, en el que se representaron "varios bailes y otros entretenimientos" ${ }^{30}$ para amenizar la espera a Felipe IV. Así, cuando la reina pasó por el palacio "la representación que divertía a su majestad del rey nuestro señor se interrumpió, dándola [se refiere a la reina], en jocoso estilo, la bienvenida un baile que a propósito interpolaba con la recitación lo cantado"31.

\footnotetext{
${ }^{28}$ Noticia, p.21.

${ }^{29}$ Noticia, p. 108.

${ }^{30}$ Noticia, p.102.

${ }^{31}$ Noticia, p. 109.
} 
En este fastuoso espectáculo no hay que olvidar que la música desempeñaba un papel fundamental, de manera que, durante todo el recorrido, la reina iba acompañada en todo momento de tambores, clarines, trompetas y chirimías, que amenizaban a los vecinos que disfrutaban de la fiesta. Además, en algunos monumentos efímeros se situaron músicos y cantores de la corte, que dedicaron diversas canciones a la reina a su paso.Uno de ellos fue la Torrecilla del Prado, en el que se situaron diversos "balcones para que por ellos se oyese, con una acordad discordia, la música de muchos instrumentos que dentro estaban prevenidos" ${ }^{\text {"32 }}$. Mucho más espectaculares debieron resultar los carros triunfales de la puerta de palacio:

Había en las tres gradas de sus popas, por las tres partes que formaban la pirámide, dieciséis ninfas en cada una, vestidas de velillo de Plata, con Lanzadas de Nácar y con sombreros de plumas blancas y mascarillas de raso negro [...]. En la plaza del carro, había otros músicos con instrumentos, vestidos de vaquero de Tela con mangas, bandas y toquillas de velilla [...]. Estos de carros, de a veinticuatro voces y seis instrumentos cada uno, ya alternados, ya juntos, se respondieron cantando desde que se descubrió el palio.

Una vez más, en la Noticia del recibimiento y entrada de la reina se transcriben todas las canciones que se oyeron durante la entrada, convirtiéndose en una fuente de inestimable precio para los estudios relacionados con la música y la sociedad de la época. La transcripción de estas letras es tan exhaustiva que incluso refleja cómo se alternaban los coros de los carros que hemos citado anteriormente:

\author{
Coro primero: Ya el ave imperial su vuelo \\ tan alto remontar pudo, \\ que pudo llegar a vista \\ del cuarto planeta augusto \\ Coro segundo: Aunque de tu voz lo creo, \\ de mi ventura lo dudo; \\ con decírmelo el rumor \\ de tantos festejos juntos \\ Ambos coros: 1 ¡Qué nueva tan dulce! \\ 2 iQué gozo tan sumo! \\ 1 ¿Qué gloria! \\ 2 ¡Qué dicha! \\ 1 ¡Qué aplauso! \\ 2 ¡Qué triunfo! ${ }^{33}$
}

\footnotetext{
${ }^{32}$ Noticia, p. 4.

${ }^{33}$ Noticia, pp. 111-112. Si bien es cierto que se han conservado todas las letras de las canciones dedicadas a la joven reina, lamentablemente no ha ocurrido lo mismo con la música, puesto que no se han conservado partituras.
} 
Para concluir, me gustaría destacar la importancia del estudio de las relaciones de sucesos como un género mixto entre el periodismo y la literatura, por la abundante información que proporciona sobre los usos y las costumbres de la época. Así, no está de más recordar que en muchas ocasiones, el análisis de estos documentos constituye la única fuente documental fiable sobre los más variados acontecimientos sociales y festivos que se produjeron durante el siglo XVII. En el caso de las relaciones que versan sobre entradas triunfales, la relación entre la literatura y la sociedad se vuelve mucho más estrecha, puesto que, como he intentado mostrar a través de la Noticia del recibimiento y entrada de Mariana de Austria en la Corte, los relatores de la fiesta no solo se esmeraban en proporcionar una abundante y minuciosa descripción del universo de la fiesta cortesana, sino que también trataban de poner de relieve la situación de España, los avatares políticos y regios de la Corte y los hábitos de la sociedad madrileña, lo que convierte a estos textos en un excelente punto de partida para llevar a cabo un análisis de conjunto y un estudio interdisciplinar de los acontecimientos más importantes que se sucedieron durante nuestro siglo XVII.

\section{OBRAS CITADAS}

ANÓNIMO: Noticia del recibimiento y entrada de la reina nuestra señora doña Mariana de Austria en la muy noble y muy leal coronada Villa de Madrid, s. 1., s. i., s. a. (1650).

BORREGO GUTIÉRREZ, Esther: "Matrimonios de la Casa de Austria y fiesta cortesana”, en Bernardo J. García García y María Luisa Lobato López (coords.), La fiesta cortesana en la época de los Austrias, Valladolid, Junta de Castilla y León-Consejería de Educación y Cultura, 2003, pp. 79-115.

BouZa ÁlvarEz, Fernando: "El espacio en las fiestas y en las ceremonias de Corte. Lo cortesano como dimensión", en Alfredo J. Morales (comisario), La fiesta en la Europa de Carlos V (Exposición), Madrid, Sociedad Estatal para la Conmemoración de los Centenarios de Felipe II y Carlos V, 2000, pp. 155-173.

Catálogo y Biblioteca Digital de Relaciones de Sucesos (siglos XVI-XVIII), Universidad de A Coruña: http://www.bidiso.es/estaticas/ver.htm?id=8

INFANTES DE MIGUEL, Víctor: “¿Qué es una relación? (Divagaciones varias sobre una sola divagación)", en Henry Ettinghausen, Víctor Infantes de Miguel, Augustín Redondo y María Cruz García de Enterría (coords.), Las relaciones de sucesos en España (1500-1750). Actas del Primer Coloquio Internacional (Alcalá de Henares, 8, 9, 10 de junio de 1995), Alcalá de Henares, Universidad de Alcalá / Publications de la Sorbonne, 1996, pp. 203-216.

LÓPEZ POZA, Sagrario: "Peculiaridades de las relaciones festivas en forma de libro", en Sagrario López Poza y Nieves Pena Sueiro (eds.), La fiesta. Actas del II 
Seminario de Relaciones de sucesos (A Coruña, 13-15 de julio de 1998), Ferrol, Sociedad de Cultura Valle-Inclán, 1999, pp. 213-222.

OlivÁn SANTALIESTRA, Laura: Mariana de Austria, Imagen, poder y diplomacia de una reina cortesana, Madrid, Editorial Complutense, 2006.

PENA SUEIRO, Nieves: Repertorio de "Relaciones de sucesos" españolas en prosa impresas en pliegos sueltos de la Biblioteca General Universitaria de Coimbra (siglos XVI-XVIII), Madrid, Fundación Universitaria Española, 2005.

SimÓn DÍAZ, José: La poesía mural en el Madrid del Siglo de Oro, Madrid, Ayuntamiento de Madrid-Instituto de Estudios Madrileños, 1977.

VARLEY, John E. y Abdón M. SALAZAR: "Calderón and the Royal Entry of 1649", Hispanic Review, 34, 1966, pp. 1-26.

ZAPATA FERNÁNDEZ DE LA HOZ, Teresa: "Las relaciones de las entradas reales del siglo XVII. Del folleto al gran libro de fiesta", en Sagrario López Poza y Nieves Pena Sueiro (eds.), La fiesta. Actas del II Seminario de Relaciones de sucesos (A Coruña, 13-15 de julio de 1998), Ferrol, Sociedad de Cultura Valle-Inclán, 1999, pp. 359-373.

: "La entrada en la Corte de Mariana de Austria. Fuentes literarias e iconografía", en Benito Navarrete Prieto, Teresa Zapata y Antonio Martínez, Fuentes y modelos de la pintura barroca madrileña, Madrid, Arco Libros, 2008, pp. 105204. 